\title{
Effect of Flood Peak Discharge Control by a Small Reservoir in an Urbanized Area-Case Study in the Kurabe River Basin, Japan
}

\author{
Kouzo Ito*, Manabu Segawa, Hiroshi Takimoto, Toshisuke Maruyama \\ Faculty of Environmental Science, Ishikawa Prefectural University, Ishikawa, Japan \\ Email: *kouzou@pref.ishikawa-pu.ac.jp, maruyama@ishikawa-pu.ac.jp
}

How to cite this paper: Ito, K., Segawa, M., Takimoto, H. and Maruyama, T. (2017) Effect of Flood Peak Discharge Control by a Small Reservoir in an Urbanized Area-Case Study in the Kurabe River Basin, Japan. Open Journal of Modern Hydrology, 7, 314-330. https://doi.org/10.4236/ojmh.2017.74018

Received: September 25, 2017

Accepted: October 28, 2017

Published: October 31, 2017

Copyright $\odot 2017$ by authors and Scientific Research Publishing Inc. This work is licensed under the Creative Commons Attribution International License (CC BY 4.0).

http://creativecommons.org/licenses/by/4.0/ (c) (i) Open Access

\begin{abstract}
Recently severe damage of flooding by urbanization was frequently occurred. To prevent this damage, small reservoir was constructed in the urbanized residential area. This paper describes an effect of flood peak discharge control by a small reservoir (control reservoir) caused by rapidly developed urbanization. Although work for this purpose was conducted, research on the effects of the control reservoir was not conducted until now. This research, conducted by simulation, was a case study in the Kurabe River Basin in the Tedori River Alluvial Fan Area, Japan, based on the precise investigation of the reservoir in the actual field. The study was conducted to determine not only the actual control reservoir capacity for the newly developed residential area but also the ideal capacity for all present residential areas and the largest capacity allowable for a maximum rainfall event that recently occurred. The control reservoir effects between individual blocks and the entire basin area were compared by dividing the test basin into 15 blocks (sub-basins). The results showed that the effects on the capacity per unit area of the residential area in blocks have close relationship with the decreasing ratio of peak discharge in blocks. Consequently, the effects of control reservoir capacity and the limitation were clarified. In the future, control reservoirs should be constructed for all of the already developed residential areas, for example, by utilizing underground car parking lot. The results of this research can contribute to the design of the control reservoir for protection against flooding damage in urbanized areas.
\end{abstract}

\section{Keywords}

Flood Control Reservoir, Discharge from Urbanized Area, Unit Flood Discharge, Peak Discharge Decreasing Ratio, Simulation of Drainage Discharge 


\section{Introduction}

Flood discharge, due to the rapid progress of urbanization from farmland since the 1960s, has caused serious damage because of a shortage of river and canal capacities. This result was because land use changed from paddy fields to residential areas. Therefore, increasing canal capacity and establishing a small reservoir to control peak flood discharge (control reservoir) were frequently undertaken. There were economic difficulties of increasing the river capacity from the developed residential area to the river mouth. Therefore, construction of a control reservoir at the end of newly reclaimed residential areas was frequently applied. Although works for this purpose were widely conducted, research on the effects of the control reservoir was not performed until now. This research focused on the effect of the control reservoir based on an actual reservoir in the Kurabe River Basin in the Tedori River Alluvial Fan Area, Japan.

Increasing flood discharge from urbanization was studied by many researchers from various perspectives. However, a runoff analysis from the macro-aspect, such as the unit hydrograph method [1] and runoff function method, is avoided because the urbanized runoff analysis from farmland requires basing on the physical properties of the basin characteristics. Here, we reviewed many research studies of a runoff analysis based on the precise and micro-aspects (i.e., based on the physical properties of the basin).

The initial research of precise urban runoff analysis was conducted by Hicks (1944) [2] and Tholin (1959) [3] using the so-called Los Angeles and Chicago method [4]. After their works, many related research projects were also conducted [4]. Following this international research, Watanabe and Toyokuni [5] conducted precise research from micro-aspects. This research was highly evaluated because it precisely investigated the networks of drainage systems in a city and analyzed runoff phenomena from hydraulics aspects. The feature of the research of runoff in a city was summarized by Toyokuni [6]. In addition, Kadoya [4] reviewed the research of runoff due to urbanization. However, the above research did not directly approach the land use changes from farmland to residential area, although the studies analyzed the urban runoff phenomenon.

There are few research studies on runoff analysis of upland and paddy field in Japan. Masumoto et al. [7] conducted research on abundant rice cultivation. Yomota and Miura [8] carried out the rotational use of paddy and upland fields, and Senge et al. [9] conducted research on the same land use. Yoshikawa et al. [10] conducted research on the discharge from the outlet of paddy lots. These research studies were limited for our aims because the properties of the basin were slightly complicated, even though these studies were based on the physical properties of the farm land. Thus, the development of micro-hydrology at farmlands has a limitation up to now.

Recently, land consolidation rapidly progressed in Japan. Therefore, the properties of the farm land were clarified, resulting in runoff analysis based on the micro-aspect becoming available, as well as an urban runoff analysis. 
Our previous research discussed unit flood discharge [11] [12], defined as the discharge that flows in the most upstream drainage canal, i.e., discharge from the smallest drainage canals. This model was applied for the Kurabe River Basin in Japan [13] [14], which had various land uses, such as paddy fields and upland and residential areas. It was used to attempt to estimate the basin discharge, including the effect of a control reservoir, as an example.

This research focused on the effect of the control reservoir on the decrease of the flood peak discharge as a case study in the Kurabe River Basin. The effects of the control reservoir were estimated following three cases: the actual capacity A for recently increased residential areas (after the related criteria were determined for 0.3 ha over residential area per plot in the cities); the ideal reservoir capacity $\mathrm{B}$ for all newly developed residential areas after the criteria were determined; and the maximum control reservoir capacity $\mathrm{C}$ for allowable maximum rainfall events that recently occurred.

This result can be used for flood damage estimation not only in Japan but also worldwide in areas that have the same urbanized runoff problems. The urbanization conducted from farmland to residential area will incur severe damage because the flood discharge increase ratio will be very large. This research does not include the over flooding of farmland levees; therefore, this situation of farmland is out of the scope of this research.

\section{Method of Research}

\subsection{Feature of the Test Basin}

The Kurabe River Basin (Figure 1) was located in the center of the Tedori River Alluvial Fan Area with an area of $17.55 \mathrm{~km}^{2}$. The entire area of the test basin shows in Figure 1. It is not in a mountainous area, and it is the same basin studied in previous research [11] [12] [13] [14]. The drainage canal plays an irrigation role in the upstream area, which is very rare in Japan. The upstream canals had concrete linings, and the downstream area is a natural river. The gradient is very steep, at 1/500, as is the Tedori River Alluvial Fan Area. Therefore, this area has not suffered backwater effects; therefore, the kinematic wave approach for the runoff analysis could be used. The urbanization mainly occurred from the paddy field. This feature should be noted for applying the method to other basins. The drainage system was precisely described in Figure 2 in previous research [14].

\subsection{Composition of Blocks}

The basin was divided into 15 blocks based on the drainage canal system, as shown in Figure 1. Table 1 describes the land use in the 15 blocks in each of the tested years. The area was investigated using a Geographical Information System (GIS) with $100 \mathrm{~m}$ mesh data [15]. The residential area contained an area of river and road that had the same runoff characteristics. The areas that did not include $100 \mathrm{~m}$ mesh data were corrected by the data coinciding with the Land Use Inves 


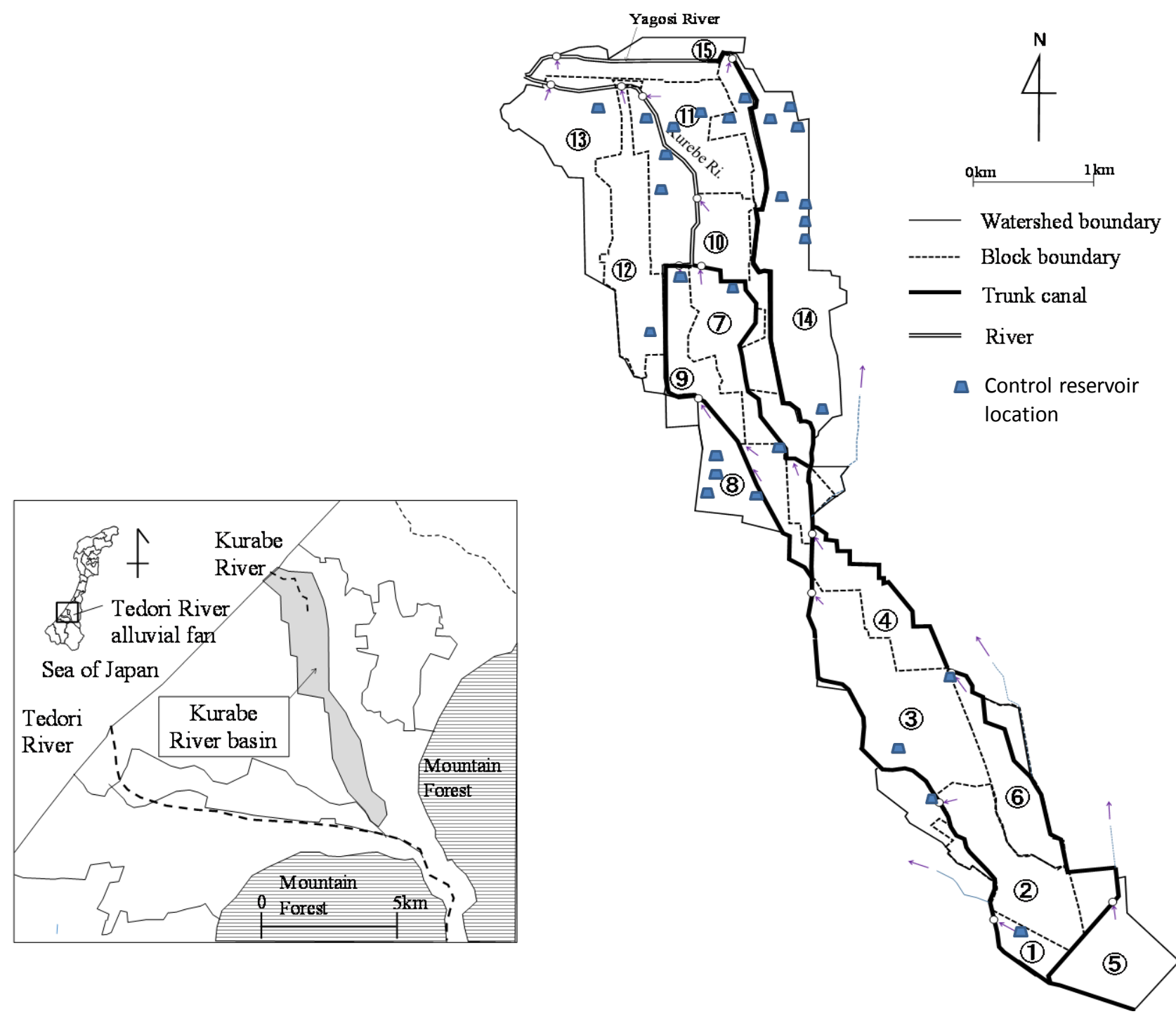

Figure 1. The Kurabe River Basin and its sub-basin (block), including the drainage system [14].
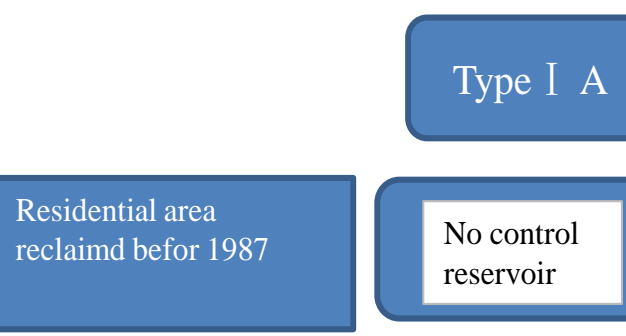

Residential area

reclaimed after 1987

0.3ha over area

Residential area

reclaimed after 1987

0.3 ha undr area
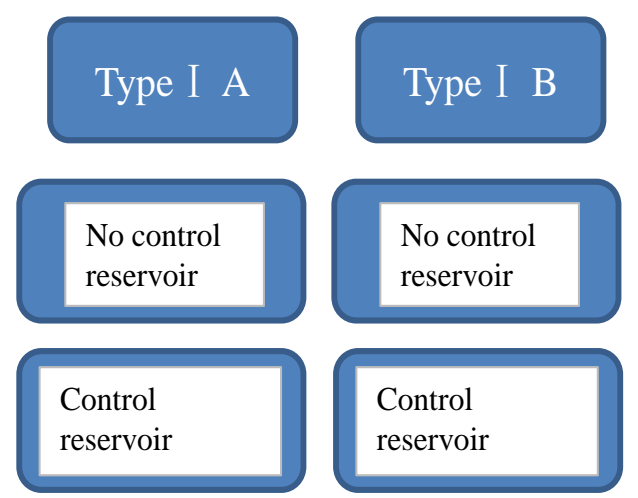

Control

reservoir
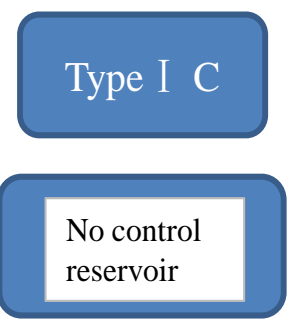

Control large reservoir

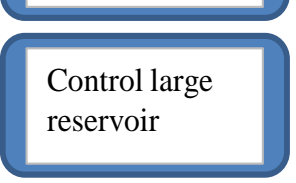

\section{Type II D}

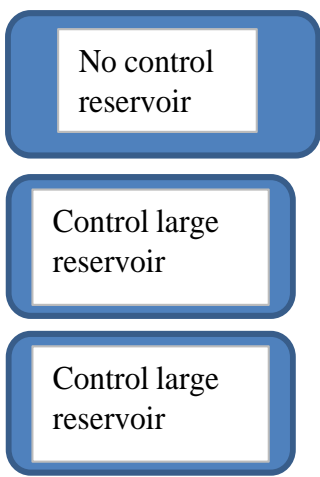

Figure 2. Simulation condition of the control reservoirs. 
Table 1. Various land use changes at individual blocks and land use in the tested years $\left(\mathrm{km}^{2}\right)$.

\begin{tabular}{|c|c|c|c|c|c|c|c|c|c|}
\hline \multirow{2}{*}{ Year } & \multirow{2}{*}{ Block No. } & (1) & (2) & (3) & (4) & (5) & (6) & (7) & (8) \\
\hline & & $2-2$ & $3-1-3$ & $3-1-2$ & $3-1-1$ & $2-1$ & $2-4$ & $3-3$ & $3-2-2$ \\
\hline \multirow{3}{*}{1987} & Paddy & 0.21 & 0.86 & 1.74 & 0.60 & 1.25 & 0.71 & 0.58 & 0.46 \\
\hline & Upland & 0.00 & 0.00 & 0.01 & 0.00 & 0.00 & 0.00 & 0.00 & 0.00 \\
\hline & Residential & 0.04 & 0.25 & 0.31 & 0.07 & 0.21 & 0.12 & 0.66 & 0.50 \\
\hline \multirow{5}{*}{2009} & Paddy & 0.14 & 0.65 & 1.67 & 0.59 & 1.11 & 0.63 & 0.27 & 0.26 \\
\hline & Upland & 0.00 & 0.00 & 0.06 & 0.00 & 0.00 & 0.00 & 0.00 & 0.00 \\
\hline & Residential & 0.11 & 0.46 & 0.32 & 0.08 & 0.35 & 0.20 & 0.97 & 0.70 \\
\hline & Area (ha) & 0.25 & 1.11 & 2.05 & 0.67 & 1.46 & 0.83 & 1.24 & 0.96 \\
\hline & Increased ratio & 2.63 & 1.84 & 1.04 & 1.13 & 1.67 & 1.66 & 1.47 & 1.40 \\
\hline \multirow{2}{*}{ Year } & \multirow{2}{*}{ Block No. } & (9) & (10) & (11) & (12) & (13) & (14) & (15) & \\
\hline & & $3-2-1$ & $\mathrm{~K}-4$ & $\mathrm{~K}-3$ & $\mathrm{~K}-2$ & $\mathrm{~K}-1$ & $3-5$ & Y & Tatal \\
\hline \multirow{3}{*}{1987} & Paddy & 0.39 & 0.47 & 1.04 & 0.92 & 0.67 & 1.45 & 0.15 & 11.49 \\
\hline & Upland & 0.00 & 0.00 & 0.00 & 0.00 & 0.00 & 0.00 & 0.42 & 0.43 \\
\hline & Residential & 0.44 & 0.02 & 0.38 & 0.27 & 0.41 & 1.26 & 0.70 & 5.63 \\
\hline \multirow{5}{*}{2009} & Paddy & 0.13 & 0.41 & 0.69 & 0.58 & 0.50 & 0.91 & 0.12 & 8.67 \\
\hline & Upland & 0.00 & 0.00 & 0.02 & 0.01 & 0.00 & 0.00 & 0.42 & 0.50 \\
\hline & Residential & 0.70 & 0.08 & 0.72 & 0.61 & 0.58 & 1.80 & 0.71 & 8.38 \\
\hline & Area (ha) & 0.83 & 0.49 & 1.42 & 1.19 & 1.08 & 2.71 & 1.26 & 17.55 \\
\hline & Increased ratio & 1.59 & 3.89 & 1.89 & 2.25 & 1.41 & 1.43 & 1.02 & 1.49 \\
\hline
\end{tabular}

tigation at Hakusan District in Ishikawa Prefecture [16]. The standard data for land use was selected as 2009 .

\subsection{Process of the Control Reservoir Setting}

To prevent flooding damage by urbanization, Ishikawa Prefecture recommended the construction of a control reservoir for newly developed residential areas after 1974. On the other hand, Hakusan City also gave the obligation (duty) to construct a control reservoir for residential developers after 2003. The recommendations were as follows:

In 1974, Ishikawa prefecture set the following criteria: [Standard of precipitation drainage treatment and capacity of small reservoir for 1.0 ha over residential area developments] [17].

In 2005, Hakusan City set the following criteria: [Standard of precipitation drainage treatment and capacity of a small reservoir for ( $0.30 \mathrm{ha} \sim 1.0 \mathrm{ha})$ of residential area development in Hakusan City] [18]. But old Mattou city set the criteria in 2003.

The contents of the latter standard state that the residential developer should guarantee the control reservoir capacity and the discharge difference before and 
after a one hour maximum discharge from the developed residential area. The estimation of discharge must be calculated by the 'Rational Formula' (the return period of planning precipitation is $1 / 10$ years, principally). According to the standard, the reservoir capacity is determined from the development area. Of course, if the drainage capacity is sufficient, there is no need to construct the reservoir.

On the other hand, the drainage capacity of the downstream of the control reservoir (maximum drainage capacity for downstream) should maintain the present downstream capacity. However, if the capacity is less than $2.5 \mathrm{~m}^{3} / \mathrm{sec} / \mathrm{km}^{2}$, the capacity can be $2.5 \mathrm{~m}^{3} / \mathrm{sec} / \mathrm{km}^{2}$ under the agreement of the river management office.

\subsection{Capacity of Actual and Examined Control Reservoir}

The data of the actual control reservoir setting investigated at the sites was collected by visiting the City Planning Division of Ishikawa Prefecture and Hakusan City. The data are shown in column A in Table 2. The location of control reservoir shows in Figure 1 There were four cases of the control reservoir tested, as shown in columns A, B, C and D. A is the control reservoir capacity of individual blocks for newly reclaimed residential areas over 0.3 ha from 1987 to 2009. B is the capacity for all newly reclaimed residential areas of the blocks during the same period. $\mathrm{C}$ is the capacity in the blocks for maximum discharge that would occur from the largest actual precipitation that recently occurred. D has a similar capacity to $\mathrm{C}$ but is of the type II reservoir mentioned later. In addition, the average capacity in depth for examined residential area is $59.3 \mathrm{~mm}$ for A (0.3 ha over residential area is $0.8 \mathrm{~km}^{2}$ ), $41.4 \mathrm{~mm}$ for B, $96.2 \mathrm{~mm}$ for C and $77.3 \mathrm{~mm}$ for D.

As shown in Table 2, the capacity ratio of $\mathrm{B}$ versus $\mathrm{A}$ is 2.40 , C versus $\mathrm{A}$ is 5.58 and $\mathrm{D}$ versus $\mathrm{A}$ is 4.48 . These results showed that the present reservoir capacity was too small when comparing cases $B$ and $C$. The detailed definitions of A, B, C and D are provided in Figure 2 and also in the footnotes of Table 2.

\subsection{Type of Control Reservoir}

For the control reservoir, many cases utilized a car parking lot, but sometimes, an individual reservoir was constructed. The type of reservoir typically is divided into two cases as shown in Figure 3. Type I, which was the main type in this area, is shown in Figure 3(a), and all flooding discharge flowed down through the control reservoir. Type II is shown in Figure 3(b), and a part of the discharge flowed down through the drainage canal with the upper limit of the canal capacity while the other discharge flowed down through the control reservoir, which seemed to be a spillway. This research conducted mainly applied type I, while additionally applying type II as a reference.

\subsection{Examined Precipitation Events}

The runoff analysis from the residential area required 10-minute intervals of precipitation data. The data from the Kanazawa Meteorological Branch was 
Table 2. Capacity of the control reservoir of blocks (standard year 2009) $\left(\mathrm{m}^{3}\right)$.

\begin{tabular}{|c|c|c|c|c|}
\hline \multirow{2}{*}{$\begin{array}{l}\text { Reservoir } \\
\text { Capacity }\end{array}$} & \multicolumn{4}{|c|}{ All newly reclaimed area 1987-2009 } \\
\hline & Over $0.3 \mathrm{ha}$ & Over 0.0 ha & & \\
\hline Block No. & Case A & Case B & Case C & Case D \\
\hline $2-2$ & 959 & 3076 & 6300 & 3900 \\
\hline $3-1-3$ & 4597 & 10,128 & 19,840 & 14,400 \\
\hline $3-1-2$ & 291 & 359 & 790 & 1880 \\
\hline $3-1-1$ & 0 & 341 & 790 & 380 \\
\hline $2-1$ & 0 & 4780 & 12,980 & 5770 \\
\hline $2-4$ & 245 & 2840 & 7250 & 3300 \\
\hline $3-3$ & 1980 & 11,300 & 30,130 & 25,650 \\
\hline $3-2-2$ & 3634 & 9472 & 18,970 & 17,280 \\
\hline $3-2-1$ & 73 & 8813 & 24,990 & 20,260 \\
\hline $\mathrm{K}-4$ & 0 & 2048 & 5260 & 2048 \\
\hline $\mathrm{K}-3$ & 12,642 & 16,466 & 33,230 & 24,860 \\
\hline $\mathrm{K}-2$ & 11,124 & 13,275 & 33,230 & 23,180 \\
\hline $\mathrm{K}-1$ & 256 & 5855 & 15,900 & 14,290 \\
\hline $3-5$ & 11,629 & 24,841 & 54,000 & 45,770 \\
\hline $\mathrm{Y}$ & 0 & 341 & 790 & 9690 \\
\hline Total & 47,430 & 113,935 & 264,450 & 212,658 \\
\hline Ratio for A & 1.00 & 2.40 & 5.58 & 4.48 \\
\hline
\end{tabular}

Note: A is actual control reservoir capacity by criteria of reference (18); B is all residential area overed by criteria of reference [18]; C is capacity for actual large precipitation not expected at design year; $\mathrm{D}$ is the same to $\mathrm{C}$ but type II.

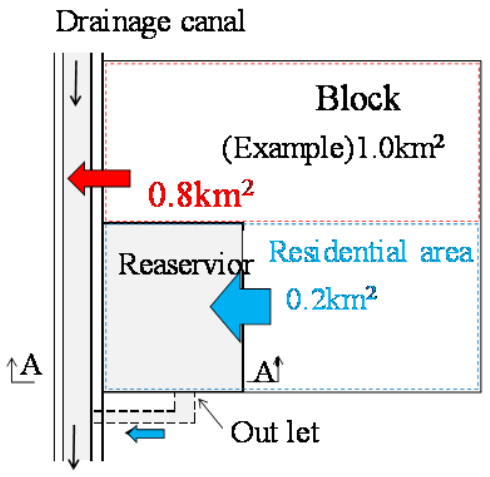

Main drainage canal

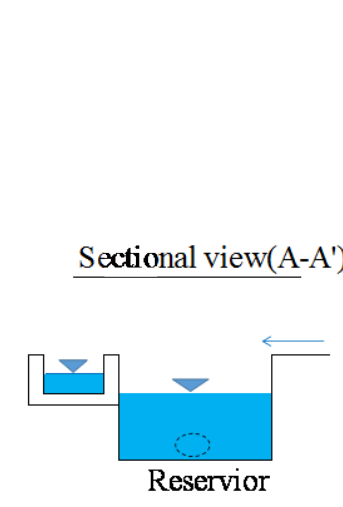

a)

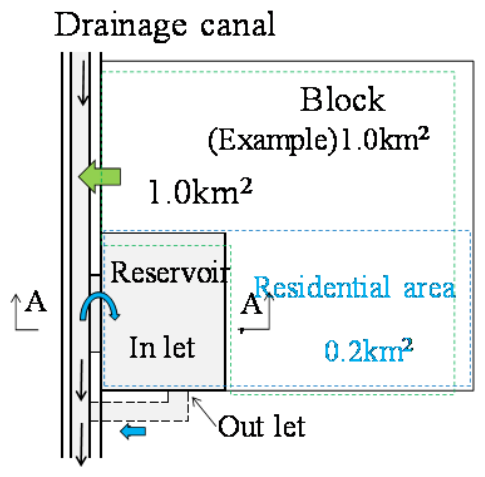

Main drainage canal $\underline{\text { Sectional view }\left(\mathrm{A}-\mathrm{A}^{\prime}\right)}$

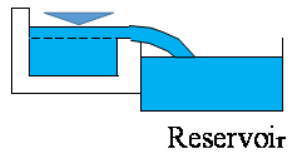

(b)

Figure 3. Type of the control reservoir for decreasing peak discharge. (a) Reservoir Type I; (b) Reservoir Type II.

selected as the test events. The data were chosen from over $80 \mathrm{~mm}$ precipitation during 24 hours by the Ishikawa Prefecture Rules, resulting in 26 events selected 
from 2009-2017. The feature of the tested precipitation, (i.e., year occurred), beginning and end time of the event, amount of the total precipitation and peak precipitation are described in Table 3 . The intensity of the peak precipitation strongly influenced the peak discharge in the residential area. A simulation was conducted by assuming that the precipitation occurred at the same time in the entire basin.

\subsection{Outline of Peak Discharge Estimation}

The peak discharge was estimated by applying the previous research results. First, we applied the unit flood discharge concept [11] [12]. This discharge was defined as flows in the most upstream drainage canal, i.e., discharge from the

Table 3. Occurrence time and total and 10 minutes intensity of tested precipitation.

\begin{tabular}{|c|c|c|c|c|c|c|c|c|c|c|}
\hline \multirow{2}{*}{$\begin{array}{c}\text { Event } \\
\text { No. } \\
\text { No. }\end{array}$} & \multicolumn{2}{|c|}{ Occurred } & \multicolumn{3}{|c|}{ Beginning } & \multicolumn{3}{|c|}{ Ending } & \multirow{2}{*}{$\begin{array}{c}\text { Total } \\
\text { Precipitation } \\
(\mathrm{mm})\end{array}$} & \multirow{2}{*}{$\begin{array}{l}\text { Maximum } 10 \\
\text { Minutes pre. } \\
\left(\mathrm{mm} \cdot 10 \mathrm{~min}^{-1}\right)\end{array}$} \\
\hline & Year & Month & Day & Hour & Min & Day & Hour & Min & & \\
\hline $3-1$ & 2012 & 7 & 6 & 11 & 0 & 7 & 13 & 20 & 127.0 & 11.0 \\
\hline $3-2$ & 2013 & 7 & 29 & 2 & 40 & 30 & 4 & 50 & 126.0 & 8.5 \\
\hline $3-3$ & 2013 & 9 & 15 & 6 & 30 & 16 & 12 & 0 & 128.0 & 3.5 \\
\hline $3-4$ & 2009 & 7 & 16 & 16 & 50 & 17 & 7 & 50 & 116.5 & 7.5 \\
\hline $3-5$ & 2013 & 11 & 17 & 20 & 50 & 18 & 21 & 0 & 109.0 & 8.5 \\
\hline $3-6$ & 2013 & 10 & 24 & 12 & 40 & 25 & 18 & 0 & 116.5 & 2.0 \\
\hline $3-7$ & 2013 & 6 & 17 & 17 & 40 & 18 & 16 & 30 & 102.5 & 5.5 \\
\hline $10-1$ & 2009 & 6 & 22 & 6 & 50 & 23 & 6 & 50 & 93.0 & 13.5 \\
\hline $10-3$ & 2011 & 5 & 29 & 1 & 10 & 30 & 10 & 30 & 104.5 & 2.5 \\
\hline $10-4$ & 2011 & 8 & 25 & 9 & 10 & 26 & 11 & 40 & 93.5 & 14.5 \\
\hline $10-5$ & 2011 & 9 & 20 & 0 & 10 & 21 & 23 & 0 & 207.5 & 5.0 \\
\hline $10-7$ & 2012 & 8 & 13 & 8 & 40 & 14 & 6 & 50 & 93.5 & 10.5 \\
\hline $10-8$ & 2012 & 9 & 10 & 20 & 0 & 11 & 15 & 20 & 94.5 & 10.5 \\
\hline $10-11$ & 2013 & 8 & 23 & 9 & 0 & 24 & 7 & 10 & 138.0 & 13.0 \\
\hline $10-13$ & 2013 & 9 & 7 & 12 & 30 & 8 & 7 & 50 & 82.0 & 5.5 \\
\hline $10-14$ & 2013 & 10 & 15 & 14 & 10 & 16 & 10 & 20 & 90.5 & 3.0 \\
\hline $10-17$ & 2013 & 11 & 20 & 0 & 20 & 22 & 0 & 0 & 136.0 & 4.0 \\
\hline $10-18$ & 2014 & 6 & 12 & 1 & 10 & 13 & 23 & 30 & 95.0 & 15.5 \\
\hline $10-19$ & 2014 & 8 & 8 & 8 & 0 & 9 & 20 & 40 & 128.5 & 7.0 \\
\hline $10-20$ & 2014 & 8 & 16 & 0 & 10 & 17 & 22 & 10 & 166.0 & 15.5 \\
\hline $10-21$ & 2014 & 12 & 4 & 0 & 50 & 5 & 22 & 50 & 122.0 & 3.0 \\
\hline $10-22$ & 2016 & 9 & 18 & 1 & 0 & 20 & 0 & 0 & 119 & 7.5 \\
\hline $10-23$ & 2016 & 9 & 28 & 4 & 10 & 29 & 11 & 10 & 89.5 & 7.5 \\
\hline $10-24$ & 2016 & 10 & 8 & 1 & 20 & 9 & 6 & 20 & 84.5 & 6 \\
\hline $10-25$ & 2017 & 6 & 30 & 16 & 0 & 1 & 20 & 30 & 134 & 10.5 \\
\hline $10-26$ & 2017 & 7 & 4 & 2 & 0 & 5 & 3 & 40 & 110 & 16.5 \\
\hline
\end{tabular}


smallest drainage canals, which was composed of discharge from paddy, upland and residential areas. Second, the basin was divided into an adequate number of blocks. The block discharge was obtained by multiplying the unit discharge by the related area of the individual land use in the block. The discharge of the various land use in the blocks was summarized. The block discharge was applied to the flood routing, according to the trunk drainage canals. Based on the above process, the discharge for the entire basin was obtained [13] [14]. The control reservoirs for newly developed residential areas were constructed at the end of residential area. The effect of the control reservoir was evaluated by comparing the decrease of the flood peak discharge with the no control reservoir case.

\section{Result of the Analysis}

\subsection{Effect of Control Reservoir for Flood Peak Discharge (Type I)}

The discharge control effect at the K-3 block, as an example, is shown in Figure 4. The horizontal axis of the figure plots the peak discharge in the case of no control reservoir, and the vertical axis plots the peak discharge in cases A, B and $\mathrm{C}$ in Table 2. The bold black line $(\mathrm{Y}=\mathrm{X}, 1: 1$ line) in the figures indicates the same values of no control reservoir discharge and controlled reservoir discharge. Thus, the difference between the bold line and plotted points describes the effects of the control reservoir for A, B and C. For Type I, the effects of flood control should appear for all events at the end of blocks because all of the flooding discharge from newly developed residential areas passed through the control reservoir.

There are data just on the bold line. These data indicate that the control reservoir had no effect. When the flood discharge before the peak discharge filled up the control reservoir, the effect did not appear. The effects differed from the precipitation patterns.

For case $\mathrm{C}$, the effect of the control reservoir was complete for the residential area developed after 1987, but it was not considered before 1987, which resulted in a constant effect, i.e., no more increase of this line.

The K-3 block had the largest and most rapid urbanization (Figure 4). In this case, the flood discharge from newly reclaimed residential areas flowed down the block; therefore, a unique and simple relationship was obtained. From the slope of the regression coefficient, the efficiency in decreasing of the discharge by the control reservoir was $22.4 \%\left(\mathrm{R}^{2}=0.913\right)$ for $\mathrm{A}, 29.0 \%\left(\mathrm{R}^{2}=0.798\right)$ for $\mathrm{B}$ and $44.7 \%\left(\mathrm{R}^{2}=0.987\right)$ for $\mathrm{C}$. The data showed that the block had a highly urbanized ratio, which indicated high control reservoir efficiency.

The effect of the control reservoir for the entire basin is shown in Figure 5. The hydrograph changed according to the flow down in the drainage canal system. The hydrograph also changed due to the precipitation pattern. Thus, the control effects appeared as shown in the figure and were slightly scattered. On the other hand, as shown in Figure 5, there was sometimes a larger discharge than for the no control reservoir case. 

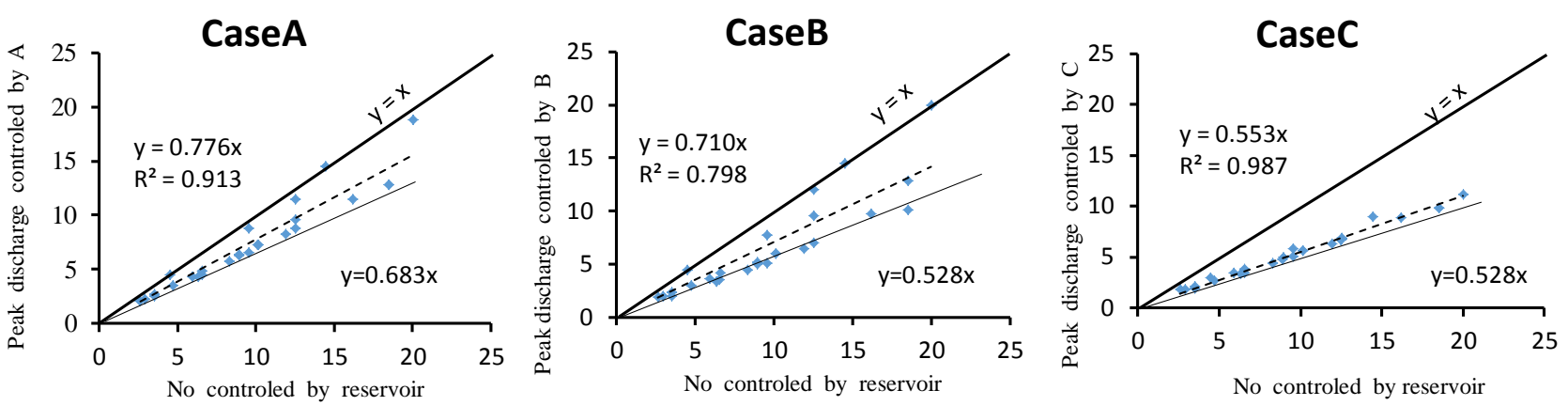

Figure 4. Peak discharge control effects by the reservoir for the K-3 block $\left(\mathrm{m}^{3} \cdot \mathrm{sec}^{-1}\right)$.
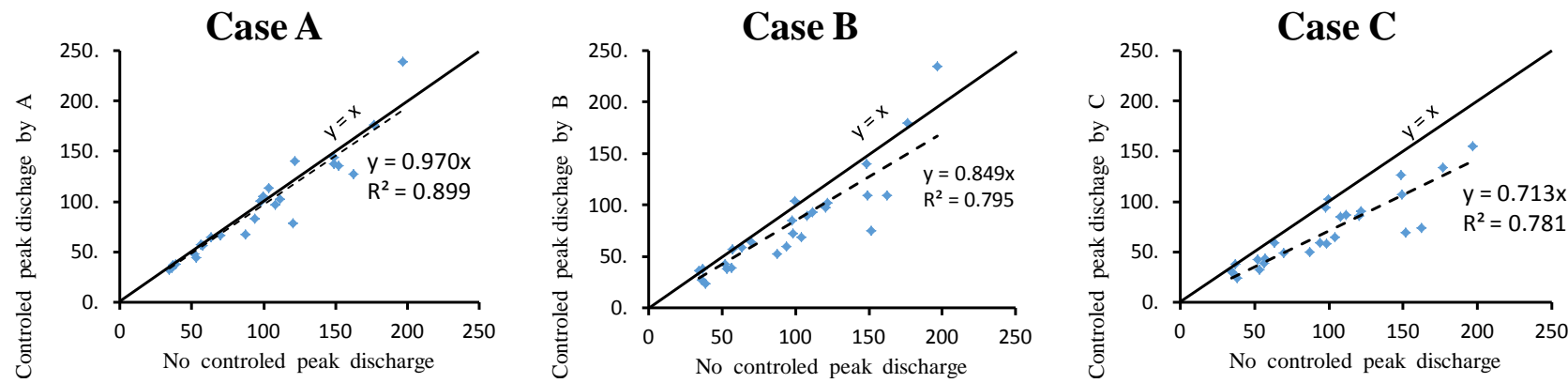

Figure 5. Peak discharge control effects of the reservoir for the entire basin (Type I) $\left(\mathrm{m}^{3} \cdot \mathrm{sec}^{-1}\right)$.

The reason for this phenomenon is the following: if the large discharge occurred at a given time due to a large amount of precipitation, the large discharge combined with the antecedent small discharge, resulting in a larger discharge appeared than in the no control reservoir case. However, this was a rare case.

The effects of the control reservoir were estimated by the slope of the regression analysis (slope of Figure 5). The slope for A was $0.970\left(\mathrm{R}^{2}=0.899\right)$, the slope for $B$ was $0.849\left(R^{2}=0.795\right)$, and the slope for $C$ was $0.713\left(R^{2}=0.781\right)$, which corresponded to a $3.0 \%$ decrease for $\mathrm{A}$, a $15.1 \%$ decrease for $\mathrm{B}$ and a 29.7\% decrease for C. The effect of the control reservoir for A for the entire basin is very small compared with the K-3 block.

\subsection{Effects of Control Reservoir for Flood Peak Discharge (Type II)}

In this case (Type II in Figure 2), the peak discharge of all residential areas reclaimed after 1987 over the main drainage capacity flowed down through the control reservoir as a spillway (as a regulating reservoir of the irrigation canal). Therefore, the effect of the control reservoir was quite different from that for Type I, as shown in Figure 6.

Figure 6(a) describes the effect for residential areas developed after 1987 for the K-3 which was most rapidly urbanized block. Figure 6(b) describes the same situation for the entire basin. As shown in Figure 6(a), the over discharge controlled was clearly constant, at approximately $37 \%$ for the decreasing ratio, which completely cut down the peak discharge. For the entire basin, based on 


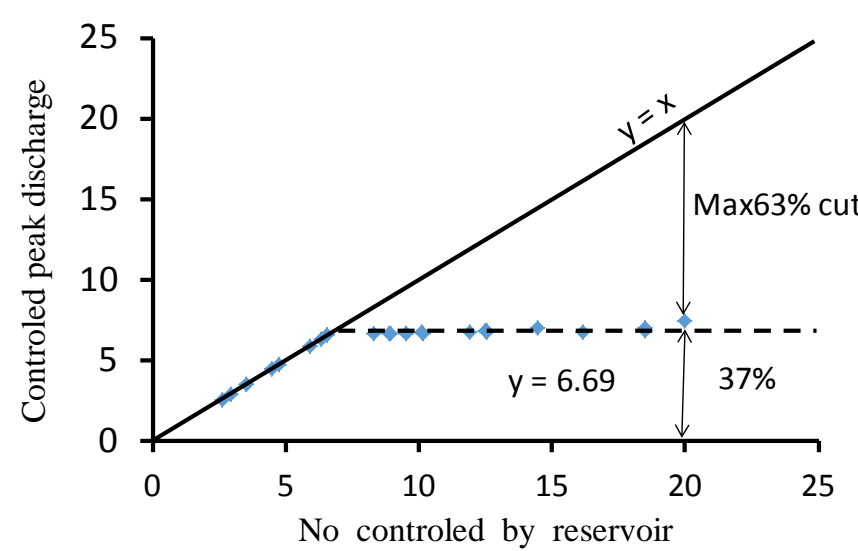

(a)

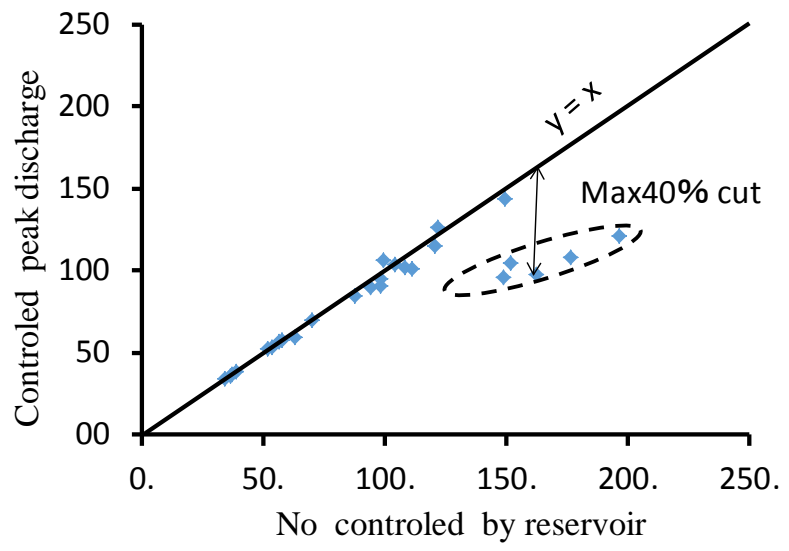

(b)

Figure 6. Peak decrease effects by the control reservoir for the K-3 block and entire basin (Type II) ( $\left.\mathrm{m}^{3} \cdot \mathrm{sec}^{-1}\right)$. (a) K-3 block; (b) Entire basin.

the discharge collected according to drainage networks, the control effect was a little different among rainfall events. However, the discharge decreased approximately $60 \%$.

\subsection{Control Reservoir Effect in a Block by Regression Coefficients for Type I}

Individual blocks had different urbanization ratios and control reservoir capacity. Accordingly, the control effect should be different among them. To clearly show the facts, based on the no control reservoir case, the effects of the control reservoir in the blocks for cases $\mathrm{A}, \mathrm{B}$ and $\mathrm{C}$ were tested using regression coefficients (Table 4).

According to the tables, the average coefficients were 0.946 (standard deviation $\sigma$ is 0.078 ) for case A, 0.810 for B ( $\sigma$ is 0.100$)$ and 0.681 for $\mathrm{C}$ ( $\sigma$ is 0.169$)$. As shown in Table 4, with the increase in the reservoir capacity, the regression coefficients decreased, and the determination coefficients varied by 0.982 for $\mathrm{A}$, with an $\mathrm{R}^{2}$ of $0.047,0.862$ for $\mathrm{B}$, with an $\mathrm{R}^{2}$ of 0.106 , and 0.956 for $\mathrm{C}$, with an $\mathrm{R}^{2}$ of 0.104, which described the unique and simple relationships.

However, the $\mathrm{R}^{2}$ for $\mathrm{B}$ and $\mathrm{C}$ in the $\mathrm{K}-4$ block were 0.656 and 0.576 , respectively, which differed from the other blocks. The reason for this result was that the discharge from paddy field mainly changed with the precipitation pattern. The ratio of paddy to residential area was large, and the increasing ratio of residential area from 1987 to 2009 was also large (Table 1).

\section{Consideration and Discussion}

\subsection{Effect of Precipitation Pattern on the Control Reservoir Capacity}

The effect of the precipitation pattern on the control reservoir capacity can be clarified. We describe the relationship as an example of the K-3 block in Figure 4. For case A, data just on the line $\mathrm{Y}=0.683 \mathrm{X}$ indicate that there was no effect of 
Table 4. Effects of the control reservoir in the blocks by regression coefficients.

\begin{tabular}{|c|c|c|c|c|c|c|}
\hline \multirow{2}{*}{$\begin{array}{c}\text { Block } \\
\text { No. }\end{array}$} & \multicolumn{2}{|c|}{ A } & \multicolumn{2}{|c|}{ B } & \multicolumn{2}{|c|}{$\mathrm{C}$} \\
\hline & Slope & $\mathrm{R}^{2}$ & Slope & $\mathrm{R}^{2}$ & Slope & $\mathrm{R}^{2}$ \\
\hline $2-2$ & 0.934 & 1.000 & 0.633 & 0.656 & 0.426 & 0.914 \\
\hline $3-1-3$ & 0.905 & 1.000 & 0.721 & 0.822 & 0.576 & 0.980 \\
\hline $3-1-2$ & 0.990 & 1.000 & 0.987 & 0.999 & 0.978 & 1.000 \\
\hline $3-1-1$ & 1.000 & 1.000 & 0.956 & 0.989 & 0.919 & 0.995 \\
\hline $2-1$ & 1.000 & 1.000 & 0.828 & 0.879 & 0.668 & 0.965 \\
\hline $2-4$ & 0.985 & 1.000 & 0.815 & 0.874 & 0.669 & 0.966 \\
\hline $3-3$ & 0.971 & 0.999 & 0.818 & 0.894 & 0.695 & 0.998 \\
\hline $3-2-2$ & 0.962 & 1.000 & 0.801 & 0.922 & 0.730 & 0.998 \\
\hline $3-2-1$ & 0.997 & 1.000 & 0.798 & 0.859 & 0.647 & 0.997 \\
\hline $\mathrm{K}-4$ & 1.000 & 1.000 & 0.729 & 0.656 & 0.462 & 0.576 \\
\hline K-3 & 0.776 & 0.913 & 0.710 & 0.798 & 0.553 & 0.987 \\
\hline $\mathrm{K}-2$ & 0.750 & 0.826 & 0.724 & 0.749 & 0.473 & 0.975 \\
\hline $\mathrm{K}-1$ & 0.993 & 1.000 & 0.826 & 0.921 & 0.726 & 0.997 \\
\hline $3-5$ & 0.925 & 0.999 & 0.808 & 0.911 & 0.712 & 0.999 \\
\hline $\mathrm{Y}$ & 1.000 & 1.000 & 0.991 & 1.000 & 0.987 & 1.000 \\
\hline Average & 0.946 & 0.982 & 0.810 & 0.862 & 0.681 & 0.956 \\
\hline$\sigma$ & 0.078 & 0.047 & 0.100 & 0.106 & 0.169 & 0.104 \\
\hline
\end{tabular}

the precipitation pattern, while data between this line and $\mathrm{Y}=\mathrm{X}$ indicate that 6 out of the 26 events had an effect. For case B, the data between $\mathrm{Y}=0.528 \mathrm{X}$ and $\mathrm{Y}$ $=\mathrm{X}$ indicated the effect of the pattern, which involved 7 out of the 26 events. For case $\mathrm{C}$, the limit line was $\mathrm{Y}=0.528 \mathrm{X}$, resulting in no data indicating an effect of the pattern. Therefore, to avoid the effect of the precipitation pattern, the control reservoir capacity should be increased until it is the same as $\mathrm{C}$.

\subsection{Relationship between the Control Reservoir Capacity per Unit Area of Block and Decreasing Ratio}

We focused on the relationship between the reservoir capacity and the decreasing ratio of the peak discharge to clarify the effects of the control reservoir. The ratio of the peak discharge increased with the control capacity, as revealed by the $\mathrm{B}$ and $\mathrm{C}$ cases. However, these relationships did not indicate a smooth relationship. The reason would depend on the area of the blocks.

Therefore, the relationship between the control reservoir capacity per unit area of the blocks and decreasing ratio of the peak discharge was investigated. Figure 7 describes the relationship. The determination coefficients of these items were 0.943 for A, 0.576 for B and 0.361 for C, which were a little improved. 

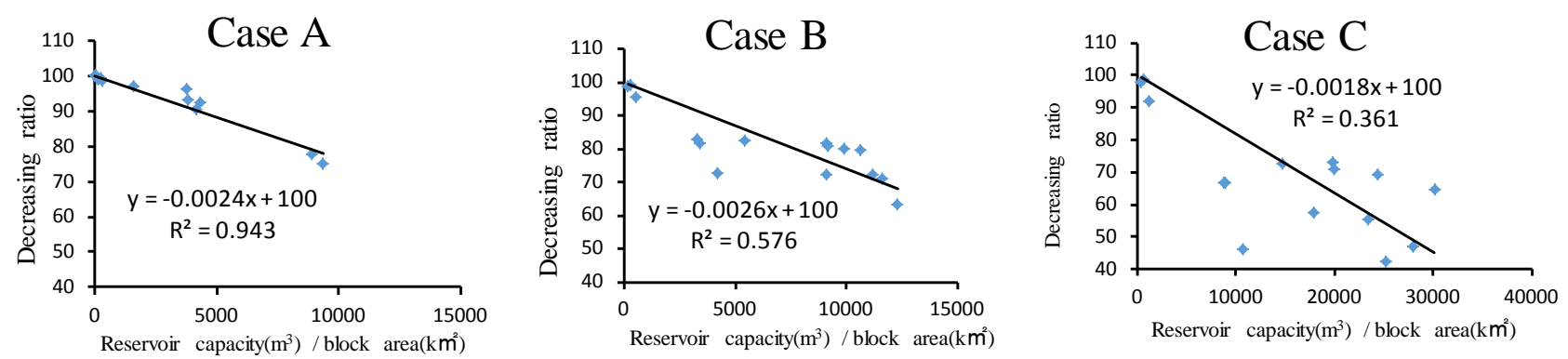

Figure 7. Relationship between control reservoir capacity per block area and decreasing ratio of peak discharge.

\subsection{Relationship between Peak Discharge Decreasing Ratio and Control Reservoir Capacity per Residential Area (2009)}

Although the control reservoir capacity was determined by the newly developed residential area, the actual effect on the decreasing ratio of the peak discharge was not evaluated. Figure 8 describes the relationship between the ratio of peak discharge and reservoir capacity per residential area (2009) in the blocks, which differed from planning concept of the reservoir. For the A, B and C cases, there was a very smooth relationship, with determination coefficients of $0.958,0.939$ and 0.977 , respectively.

The ratios of peak discharge were $25.0 \%$ for $\mathrm{A}, 36.7 \%$ for $\mathrm{B}$ and $57.4 \%$ for $\mathrm{C}$ at the maximum, which corresponded with control reservoir capacity from A to $\mathrm{C}$. According to the flood runoff from the residential area, the peak discharge would be determined by the peak precipitation, not the precipitation pattern. This fact indicated that the peak discharge decreased according to control reservoir capacity per unit area of residential area in the individual blocks. The control reservoir functioned well, according to the planning concept.

However, the averages of the control reservoir capacity for B, C against $\mathrm{A}$ were remarkably large as in Table 2, while the decreasing ratio of the peak discharge was not as large as mentioned before. This result shows that the decreasing ratio has non-linear relationship with the control reservoir capacity as shown in Figure 9. The peak discharge controlled by a small reservoir had a limitation.

\section{Discussion}

\subsection{Consideration of the Effects on Individual Blocks and the Entire Basin}

The reason for the difference in the control reservoir effects in blocks and the entire basin was considered. The relationship was strictly indicated in Figure 4 and Figure 5. For the case of A, the former showed $22.4 \%$ discharge decrease efficiency, while the latter showed 3.0\%. The reason for these results was because the lag time between peak precipitation and peak discharge, which was relatively small in the block, while it was rather large in the entire basin. In other words, the peak discharge was average in the large area and not in the small area, resulting in a high decreasing effect in the small area. The decreasing effect of peak discharge was large in the block, especially rapidly urbanized blocks, even if the 
Case A

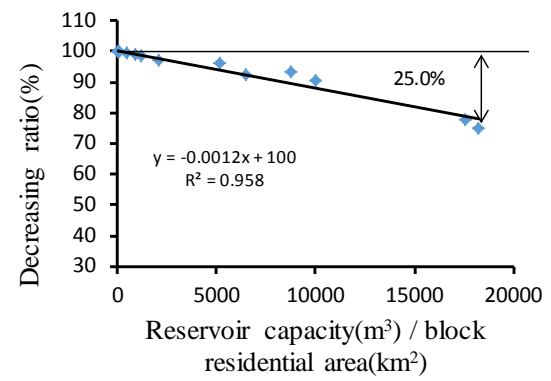

Case B

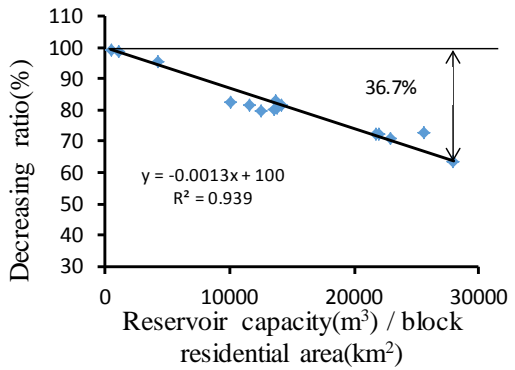

Case C

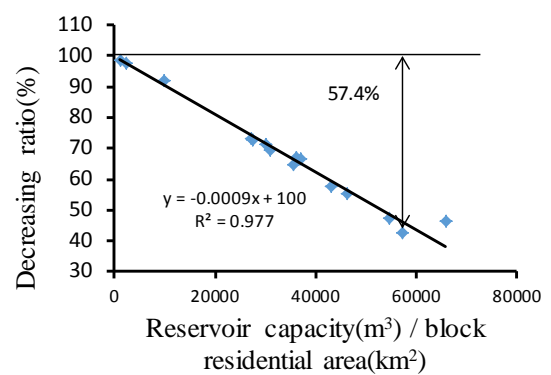

Figure 8. Relationship between the decreasing ratio of the peak discharge and reservoir capacity per residential area.

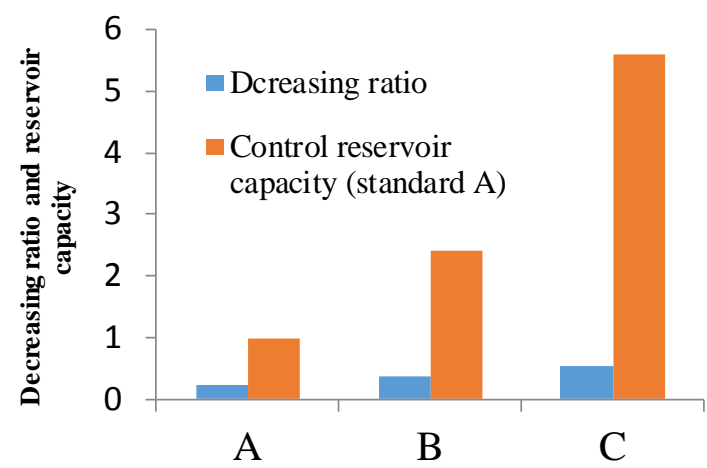

Figure 9. Relationship of peak decreasing ratio and control reservoir capacity.

effects of the entire basin seemed to be small. In addition, the total discharge did not change, even though the peak discharge was averaged.

\subsection{Lag Time of Flow in a Block}

This research did not consider the lag time for flow down the drainage channel in a block. Theoretically, this lag time should be taken into considered. However, neither the actual location of the residential area nor the specified drainage canal for individual land use was cleared. Therefore, the flood routing for runoff discharge for a residential area was very difficult. The main aim of the research was the decreasing ratio of peak discharge obtained with the use of the control reservoir; thus, the lag time of flow down a block was not very important. However, for a type II control reservoir, the flood routing can be available because the drainage channel has already been determined for various land use scenarios. As a result of this trial, the decreasing ratio of the peak discharge did not change, but the peak discharge slightly decreased.

\subsection{Problems Future to be Consider}

However, as discussed above, control reservoir construction for newly developed residential areas is not sufficient to prevent flooding damage. Therefore, we consider the control reservoirs should be constructed for all residential areas, including already developed areas. Furthermore, there were many cases where the 
actual control reservoir was also constructed for the car parking with concrete pavement, thus, the percolation of water into the ground was limited. We should be considering not only flood control but also ground water recharge.

\section{Summary and Conclusions}

This paper described the effect of a control reservoir for peak flood discharge from an urbanized area aiming to decrease flood damage. The research was conducted by investigating an actual control reservoir in the Kurabe River Basin located in the Tedori River Alluvial Fan Area, Japan. The function of the control reservoir was investigated by simulation from hydrological and hydraulic aspects.

First, the capacity of the control reservoir in this area was investigated for case $A$ and assumed for cases $B$ and $C$. The effect of the control reservoir was examined for these three cases. For the K-3 block, which was most urbanized block in the basin, the peak decreasing ratios were $22.4 \%, 29.0 \%$ and $44.7 \%$ for cases $\mathrm{A}$, $\mathrm{B}$ and $\mathrm{C}$, respectively. The peak decreasing ratios for the entire basin were $3.0 \%$, $15.1 \%$ and $29.7 \%$ for cases A, B and C, respectively. These results showed that the control reservoir effects on the high urbanized block showed a high decreasing ratio of the peak discharge.

The effect of the control reservoir on 15 blocks having different urbanized ratios was investigated using peak discharge regression coefficients between cases $\mathrm{A}, \mathrm{B}$ and $\mathrm{C}$ and the no control reservoir case. The peak discharge decreasing ratio had a very clear relationship with the control reservoir capacity per unit residential area in the blocks, which resulted in it having less of a relationship with the precipitation pattern.

On the other hand, the effects of the reservoir seemed to be relatively small for the entire basin, while the effect was relatively large in the individual blocks. The effect was remarkably large in the highly urbanized block. The above results were not found in previous research; therefore, they will contribute to the design of control reservoirs.

As mentioned above, the control reservoir was not sufficient. Therefore, the reservoir should be constructed for all residential areas. For example, the underground car parking lots of homes should be an adequate place for control reservoir construction. For example, the capacity of $50-60 \mathrm{~mm}$ in depth multiple to the home lots of areas should be constructed. On the other hand, the reclamation of residential areas should be limited, i.e., the adequate farmland area should be maintained in a region.

In the Tedori River Basin, the utilization of ground water is very important, especially the use of ground water from snow melting. Therefore, the concrete pavement should be changed to a pervious material. The effluent of water into the ground should be considered in the future as an important issue.

In addition, this research was conducted from the aspect of decreasing the flood peak discharge. However, if the peak discharge occurred instantaneously 
and it acceptable for the related people, the peak discharge amount would be outside of the planning concept because of cost- performance issues.

\section{Acknowledgements}

We express great thanks to Ishikawa prefecture and Hakusann City for valuable data on drainage and for Dr. Keiji Takase and Youichi Fujihara, professor and associate professor of Ishikawa Prefectural University for valuable comments.

\section{References}

[1] Eaglesonn, P.S. (1962) Unit Hydro Characteristics for Sewered Areas, Proceedings of the American Society of Civil Engineers, Proceedings Paper 3069, Mas, 1962, 88-HY2, 1-25

[2] Hicks, W.L. (1944) A Method of Computing Urban Runoff. Transaction of Civil Engineering, 109, 1217-1253

[3] Tholin, A,L. and Keifer, C.J. (1959) The Hydrology of Urban Runoff, Proceedings of the American Society of Civil Engineers, March 1959, 85-SA2, 47-106

[4] Kadoya, M. (1985) A Review of the Study on Changes Due to Urbanization. Transaction of Civil Engineering, No. 363/ II -4, 23-34.

[5] Watamabe, M. and Toyokuni, E. (1989) Urban Catchment Modeling and Storm Water Runoff Simulations, Natural Disaster Science, 8, 46-63.

[6] Toyokuni, E. (1982) Modeling of Urban Runoff System, Water Works, Series of Hydraulics. Civil Engineering, 82, 3.

[7] Takao, M., Manabu, N., Akiko, Y. and Shuh, M. (2003) A Study Runoff Model in Hilly Rural Area for Evaluating Runoff Change Due to Abundant Rice Cultivation. Journal of Irrigation, Drainage and Rural Engineering, 224, 35-44.

[8] Yomota, A. and Miura, T. (1982) Study on Surface Discharge from Rotational Use of Paddy Field. Journal of Agricultural Engineering, 50, 19-23.

[9] Senge, M., Nishide, T. and Adach, T. (1987) Runoff Simulation Model and Unit Area Surface Design Peak Runoff Coefficients of Rotational Paddy Field. Journal of Irrigation, Drainage and Rural Engineering, 131, 43-50.

[10] Nnatsuki, Y., Noki, N. and Shin-ich, M. (2009) Evaluation Runoff Retention Function of Paddy Field Installed with Runoff Control Devices. Journal of Irrigation, Drainage and Rural Engineering, 261, 31-39.

[11] Segawa, M., Maruyama, T. and Takase, K. (2016) Estimation of Rainfall-Runoff Discharge from Unit Area of Paddy, Upland and Residential Area in the Tedori River Alluvial Fan Area. Journal of Irrigation, Drainage and Rural Engineering, No. 302, 103-112.

[12] Manabu, S., Maruyama, T. and Takase, K. (2016) Estimation of Unit Flood Discharge for Various Land Use Types with a Focus on Urbanization. Journal of Modern Hydrology, 6, 195-211. https://doi.org/10.4236/ojmh.2016.64016

[13] Segawa, M., Maruyama, T. and Takase, K. (2017) Change in Flood Discharge Due to Urbanization-Case Study in the Kurabe River Basin in Tedori River Fan, Japan. Journal of Irrigation, Drainage and Rural Engineering, No. 305, 71-81.

[14] Segawa, M., Ito, K. and Maruyama, T. (2017) Flood Discharge Changes by Urbanization from Farmland Based on the Unit Flood Concept at the Kurabe River, Japan. Journal of Modern Hydrology, 7, 223-243. https://doi.org/10.4236/ojmh.2017.73013 
[15] Ministry of Land, Infrastructure, Transport of Japan (2016) National Land Information Division, National Spatial Planning and Regional Policy Bureau, National Land Numerical Information Download Service.

http://nlftp.mlit.go.jp/ksj/gml/datalist/KsjTmplt-L03-a.html

[16] Ishikawa Prefecture (2011) Land Use Investigation at Hakusan District in Ishikawa Prefecture.

[17] Ishikawa Prefecture (1974) Standard of Storm Discharge Estimation and Control Reservoir Capacity.

http://www.city.hakusan.ishikawa.jp/data/.../sidouyoukou28.4.1-.pdf

[18] Hakusan City (2005) Standard of Storm Discharge Estimation and Control Reservoir Capacity for Small Scale.

http://www.city.hakusan.ishikawa.jp/data/.../sidouyoukou28.4.1-.pdf 